\title{
Health Professionals Oral Health Knowledge and Practice: Unleashing the Hidden Challenges
}

This article was published in the following Dove Press journal:

Journal of Multidisciplinary Healthcare

\author{
Dawit Kumilachew Yimenu (D) \\ Eyerusalem Shello Adelo ${ }^{2}$ \\ Ebrahim Abdela Siraj $\mathbb{D}^{3}$ \\ Tadael Assaye Kassie ${ }^{4}$ \\ Workineh Woldeselassie \\ Hammeso 5 \\ Chilot Abiyu Demeke (D) \\ Yohannes Kelifa Emiru iD ${ }^{6}$ \\ 'Department of Pharmaceutics and Social \\ Pharmacy, School of Pharmacy, College of \\ Medicine and Health Sciences, University \\ of Gondar, Gondar, Ethiopia; \\ ${ }^{2}$ Department of Midwifery, College of \\ Medicine and Health Sciences, University \\ of Gondar, Gondar, Ethiopia; \\ ${ }^{3}$ Department of Pharmacy, College of \\ Medicine and Health Sciences, Bahir Dar \\ University, Bahir Dar, Ethiopia; \\ ${ }^{4}$ Department of Internal Medicine, Addis \\ Alem Hospital, Bahir Dar, Ethiopia; \\ ${ }^{5}$ Department of Pharmacy, College of \\ Health Sciences, Mizan-Tepi University, \\ Mizan Teferi, Ethiopia; ${ }^{6}$ Department of \\ Pharmacognosy, School of Pharmacy, \\ College of Medicine and Health Sciences, \\ University of Gondar, Gondar, Ethiopia
}

Correspondence: Dawit Kumilachew Yimenu

Department of Pharmaceutics and Social Pharmacy, School of Pharmacy, College of Medicine and Health Sciences, University of Gondar, P.O. Box 196, Gondar, Ethiopia Tel +25I 920760099

Email dawitkumilachew@yahoo.com

\begin{abstract}
Objective: Dental disease is one of the major prevalent preventable public health challenges that resulted in a significant burden on children and adults. The aim of the current study was to identify oral health-related knowledge and practice among Bahir Dar community health care providers and the perceived barriers to oral health care services.

Methods: A cross-sectional study was conducted. A self-administered, structured questionnaire was used for data collection, and SPSS version 20 was used for data analysis. A chisquare test was used to determine the association between study variables, and a P-value of less than 0.05 was considered to declare statistical significance.

Results: A total of 281 interviews were conducted. Doctors had the highest mean knowledge score value of 4.67 followed by dentists with a mean score of 4.5 . The majority of the study participants (59.4\%) reported that they use a toothbrush and fluoride toothpaste for brushing their teeth, and a statistically significant difference was observed between different types of health professionals. The majority of the study participants (80.1 and 70.8\%) reported limited finances and lack of adequate health/dental insurance as a barrier to oral health care services, respectively.

Conclusion: Oral health-related knowledge of health professionals in Bahir Dar city is low. Oral health topics must be incorporated into the health care professionals training programs and continuing medical education. Health professionals should master basic oral healthrelated knowledge, and they should practice basic oral health care practices to become role models for their patients.
\end{abstract}

Keywords: oral health, dental care, health professionals, tooth brushing, health practice

Oral health is one of the fundamental components of general health. ${ }^{1}$ Oral health does not only mean healthy teeth. The World Health Organization (WHO) defined good oral health as "free of chronic mouth and facial pain, oral and throat cancer, oral sores, birth defects such as cleft lip and palate, periodontal (gum) disease, tooth decay, and tooth loss, and other diseases and disorders which affect the mouth and oral cavity". 2

Dental disease is one of the major prevalent preventable public health challenges that resulted in a significant burden on children and adults. There are so many oral diseases having important impact on general health, whereas systemic diseases may also bring a mutual influence on oral health. As such, it should be incorporated into comprehensive health-promoting strategies and practices as well as addressed in a multi-professional approach. ${ }^{3}$ Essentially, the combined effort of the medical and dental professions is needed for total health care. Oral health promotion is important in the health care practices of health professionals. Physicians have a very good opportunity to promote 
oral health practices as they regularly meet children with their care givers routinely in child-care clinics. ${ }^{4}$

Awareness of the public about dental diseases and oral health, dental services utilization, application of dental sealants and self-care that include daily flossing and brushing with fluoride-containing dentifrice are some of the reported predictors of oral diseases and oral health promotion. ${ }^{5,6}$ Underserved and high-risk communities do not usually perceive the importance of oral health or benefits gained by regular dental care even though public awareness can be useful in reducing and probably eliminating oral health problems. ${ }^{5}$ Better understanding of oral health perspectives during life stages at the individual and community levels is needed for an early intervention, including management of dental disease and age-specific prevention and counseling. ${ }^{6}$

Improving awareness of the public and promoting better utilization of dental check-up may aid in early diagnosis. ${ }^{1}$ It is important to provide adequate information on oral diseases including risk factors as well as preventive measures need to be provided to the affected population. About $80 \%$ of dental problems can be prevented with good oral hygiene and it is the basis for a healthy mouth. ${ }^{7}$ Primary prevention through teeth brushing has paramount importance in the prevention of dental health problems. ${ }^{8}$ Developing countries and the poor population in general constitute the higher burden of oral diseases. ${ }^{9}$ A similar study done in Kenyan school children showed that $93 \%$ of the children used fluoride with a toothbrush, $87 \%$ of them knew that dental caries and periodontitis are preventable. ${ }^{10}$

Oral hygiene practices vary in different countries. For instance, tooth brushing is practiced in Korea in which $97 \%$ of Koreans brush their teeth once a day, ${ }^{11}$ while in India, about $69 \%$ of the population brushed their teeth. ${ }^{12}$ A survey in Pakistan showed that $36 \%$ of the population cleaned their teeth daily. ${ }^{13}$ In Saudi Arabia, $83 \%$ of schoolchildren used a toothbrush for oral hygiene while $16 \%$ used a chewing stick. ${ }^{14}$ However, in Tanzania, it was reported that $92 \%$ of children did not brush their teeth every day. ${ }^{15}$ In Ethiopia, oral health gets low attention from the government and the existing dental services are limited. Furthermore, health professional's knowledge and oral health practice is not much known in Ethiopia and their knowledge and practice is very important because they are care givers for patients and are also role models for the community. The aim of the current study was to assess oral health-related knowledge and practice among Bahir Dar community health care providers and the perceived barriers to oral health and dental care services.

\section{Methods and Materials}

\section{Study Area and Period}

The study was conducted among health care providers in Bahir Dar city, Northwest Ethiopia. Bahir Dar is the capital city of Amhara National Regional State. It is situated $565 \mathrm{~km}$ from Addis Ababa. Bahir Dar is a special Zone which has 17 kebeles. Its population is estimated at around 249,851 projected from the 2007 national census. ${ }^{16}$ Public health facilities in the City are two Governmental Referral Hospitals, 2 private hospitals, 10 health centers, 22 private clinics (3 higher private clinics, 7 special private clinics, and 12 private medium clinics), 14 pharmacies, 32 drug shops and 8 rural drug vendors. The data was collected from June 1, 2018, to August 30, 2018.

\section{Study Design}

A cross-sectional study was conducted to assess oral health-related knowledge and practices of different health care professionals working at different health facilities in Bahir Dar city together with the perceived barriers to oral health care services.

\section{Population}

\section{Source Population}

The source populations of the study were all health care professionals who were working at different health care facilities of Bahir Dar city.

\section{Study Population}

All health care professionals that fulfilled the inclusion criteria and who were available at the time of data collection.

\section{Inclusion and Exclusion Criteria Inclusion Criteria}

All health professionals who were working at least for 6 months at public or private health facilities in Bahir Dar city.

\section{Exclusion Criteria}

Health professionals who were not willing to participate in the study.

\section{Sampling Technique and Sample Size Determination}

As there is no available data on the proportion of health professionals currently practicing in each of health facilities, all of the consenting health professionals working in 
the health facilities were invited to participate in the survey.

\section{Study Variables}

Sociodemographic characteristics of the study participants (Sex, Age, Profession, Experience, Type of health facility) were analyzed against the dependent variables (knowledge and oral health practice).

\section{Data Collection Procedures}

A self-administered structured questionnaire was designed and distributed among three hundred health professionals working at different health facilities in the city in which 281 of them were returned being filled completely. The questionnaire consisted of four parts. The first part comprised questions relating to demographic characteristics of the study participants (age, gender, education, type of health profession, professional experiences, type of health facilities, and three close ended questions assessing previous training regarding oral health, information access related to oral health and dental products and their source of information). The second part consisted of nine questions to assess oral health knowledge (frequency of teeth to be cleaned, correct method of brushing a teeth, what healthy gums look like, what kind of dental problems need an intervention by a dentist, frequency should a dentist be visited, whether oral health affect rest of the body, the best method to prevent tooth decay, whether sugary diets affect oral health and the importance of fluoride tooth paste and mouth wash products in dental hygiene). The third part consisted of 6 questions to assess respondents oral health practice and the final part of the questionnaire consisted of nine questions to assess barriers to oral health and dental care services. The data was collected by four pharmacy professionals.

\section{Data Processing and Analysis}

A score of "zero" was given for every wrong answer and a score of "one" was given for every right answer in the oral health knowledge score. The individual scores were then summed to gain a final score. The highest possible score in this technique was nine; if the study participants answered all the questions correctly and the lowest was zero; if the answers were all wrong. Mean percentage scores were also calculated between the different health professionals. Chi-square test was conducted in order to detect if there was a significant difference among health professionals with regard to knowledge and practice towards dental treatment and oral hygiene practices and $\mathrm{P} \leq 0.05$ was considered statistically significant. The data was analyzed using SPSS version 20.

\section{Data Quality Assurance}

Two days of training was given to the data collectors. The data was collected by four pharmacy professionals who worked outside Bahir Dar city. The data collectors were supervised daily by two supervisors. The questionnaire was pretested on $5 \%$ of the calculated sample size who were then excluded from the main study. Depending on the result of this pilot study the questionnaire was modified and distributed among health professionals working in varies health facilities. The collected data were checked for completeness, accuracy, and consistency at the end of each day.

\section{Ethical Consideration}

Ethical clearance was obtained from the ethical review committee of School of Pharmacy (SoP), College of Medicine and Health Sciences (CMHS), University of Gondar (UoG) with approval number of UoG-CMHSSoP-154/2019 and was administered to each study participant before the data collection procedure. All of the study participants were provided with clear explanations about the purpose of the study and consent to participate in the study was obtained. The collected data were kept confidential and were used for the purpose of the study only.

\section{Results}

A total of 281 health professionals participated in the study giving a response rate of $93.7 \%$. Cronbach's $\alpha$ test was conducted to test for reliability of the data collection tool and it was found to be 0.805 . The majority of the study participants were male $(52.7 \%)$ with more than two-thirds of the participants being within the range of 26-35 years of age (Table 1). The majority of the study participants $248(88.3 \%)$ reported that they have not ever received training on oral health. More than two-thirds of the participants also reported that they did not have easy access to information regarding oral health and dental products 197 (70.1\%). The major sources of information reported by the participants were newspapers and magazines $23.8 \%$, medical references books $15.3 \%$, mass media (TV/radio) 18.9\%, Dental products information sheets (leaflets, brochures, posters, etc.) 18.9\%, Family/ friends/neighbors $23.1 \%$. The majority of nurses (57.1\%), midwives (54.2\%) and pharmacists (53.6\%) 
Table I Socio-Demographic Characteristics of The Study Participants $(\mathrm{N}=28 \mathrm{I})$

\begin{tabular}{|c|c|c|c|}
\hline \multicolumn{2}{|c|}{$\begin{array}{l}\text { Socio-Demographic } \\
\text { Characteristics }\end{array}$} & \multirow{2}{*}{$\begin{array}{l}\text { Frequency } \\
148\end{array}$} & \multirow{2}{*}{$\begin{array}{l}\text { Percentage } \\
\text { (\%) }\end{array}$} \\
\hline Sex & Male & & \\
\hline & Female & 133 & 47.3 \\
\hline \multirow[t]{3}{*}{ Age } & $18-25$ & 46 & 16.4 \\
\hline & $26-35$ & 204 & 72.6 \\
\hline & $>35$ & 31 & II \\
\hline \multirow[t]{6}{*}{ Profession } & Doctor & 36 & 12.8 \\
\hline & Pharmacist & 69 & 24.6 \\
\hline & Nurse & 77 & 27.4 \\
\hline & Midwife & 72 & 25.6 \\
\hline & Dentist & 12 & 4.3 \\
\hline & Radiographer & 15 & 5.3 \\
\hline \multirow[t]{3}{*}{ Experience } & $<5$ years & 155 & 55.2 \\
\hline & $5-10$ years & 96 & 34.2 \\
\hline & $>10$ years & 30 & 10.7 \\
\hline \multirow[t]{5}{*}{$\begin{array}{l}\text { Type of health } \\
\text { facility }\end{array}$} & $\begin{array}{l}\text { Specialized } \\
\text { hospital }\end{array}$ & 59 & 21 \\
\hline & General hospital & 145 & 51.6 \\
\hline & $\begin{array}{l}\text { Primary health } \\
\text { center }\end{array}$ & 15 & 5.3 \\
\hline & $\begin{array}{l}\text { Drug retail } \\
\text { outlets }\end{array}$ & 15 & 5.3 \\
\hline & $\begin{array}{l}\text { Private hospital/ } \\
\text { clinic }\end{array}$ & 47 & 16.7 \\
\hline
\end{tabular}

reported that "oral health and hygiene was not incorporated in their study program while they were a student".

\section{Oral Health Knowledge}

Based on the type of health professionals, it was observed that doctors had the highest mean score value of 4.67 followed by dentists with a mean score of 4.5. Radiographers had an average score of 3.27 , while pharmacists, nurses, and midwives had an average score of 3.05, 3.02 and 2.75 respectively. A greater number of dentists $58.3 \%$ followed by doctors $52.8 \%$, nurses $40.3 \%$, pharmacists $34.8 \%$, radiographers $26.7 \%$ and midwives $25 \%$ answered correctly that teeth should be cleaned twice per day. There was a statistically significant difference with regard to the health profession $(\mathrm{P}=0.006)$. A greater number of radiographers $20 \%$ followed by nurses $18.2 \%$, midwives $18.1 \%$, doctors $16.7 \%$, dentists $16.7 \%$ and pharmacists $13 \%$ answered that healthy gums look like pink and firm.

More number of dentists (66.7\%) followed by doctors (61.1\%), pharmacists $47.8 \%$, nurses $42.9 \%$, midwives $40.3 \%$ and radiographers $40 \%$ agreed that sugary diets like soft drinks and juices cause tooth decay. The same number of dentists and doctors $(66.7 \%)$ followed by pharmacists $37.7 \%$, midwives $22.2 \%$, nurses $22.1 \%$ and radiographers $6.7 \%$ reported that "a dentist should be visited one to two times a year". The difference was also statistically significant with regard to health professionals $(\mathrm{P}<0.001)$ and experience $(\mathrm{P}=0.003)$. To the question "which need a dental intervention", the majority of doctors $83.3 \%$, midwives $47.2 \%$, nurses $44.2 \%$ and dentists $41.7 \%$ answered that both dental calculus and dental plaque need intervention while the majority of pharmacists $31.8 \%$ answered they do not know and equal number of radiographers (33.3\%) answered only dental plaque, only dental calculus, and both plaque and dental calculus. There was a statistically significant difference among respondents with regard to the profession $(\mathrm{P}=0.006)$ and experience $(\mathrm{P}=0.022)$.

The majority of doctors $61.1 \%$, dentists $41.7 \%$, nurses $31.2 \%$ and pharmacists $29 \%$ answered that the correct method of brushing teeth is horizontal while the majority of radiographers $40 \%$ and midwives $29.2 \%$ answered that it is circular. The difference was statistically significant with regard to the health profession $(\mathrm{P}=0.005)$ and experience $(\mathrm{P}=0.03)$. To the question "What is the best method to prevent tooth decay," a greater number of doctors (88.9\%) followed by radiographers $(66.7 \%)$ answered that the best method to prevent tooth decay is brushing teeth regularly (Figure 1). The difference was also statistically significant with regard to the health profession $(\mathrm{P}=0.017)$ and experience $(\mathrm{P}=0.003)$.

The majority of the health professionals; doctors (86.1\%), dentists $66.7 \%$, nurses $44.2 \%$, midwives $40.3 \%$, radiographers $40 \%$ and pharmacists $37.7 \%$ answered that oral health affects the rest of the body. The difference was statistically significant with regard to the health profession $(\mathrm{P}<0.001)$ and experience $(\mathrm{P}=0.029)$. Similar results were found when asked about whether products like fluoride toothpaste and mouth wash were important in dental hygiene, the majority of doctors (86.1\%) answered "yes" compared with the other health professionals (Figure 2). 


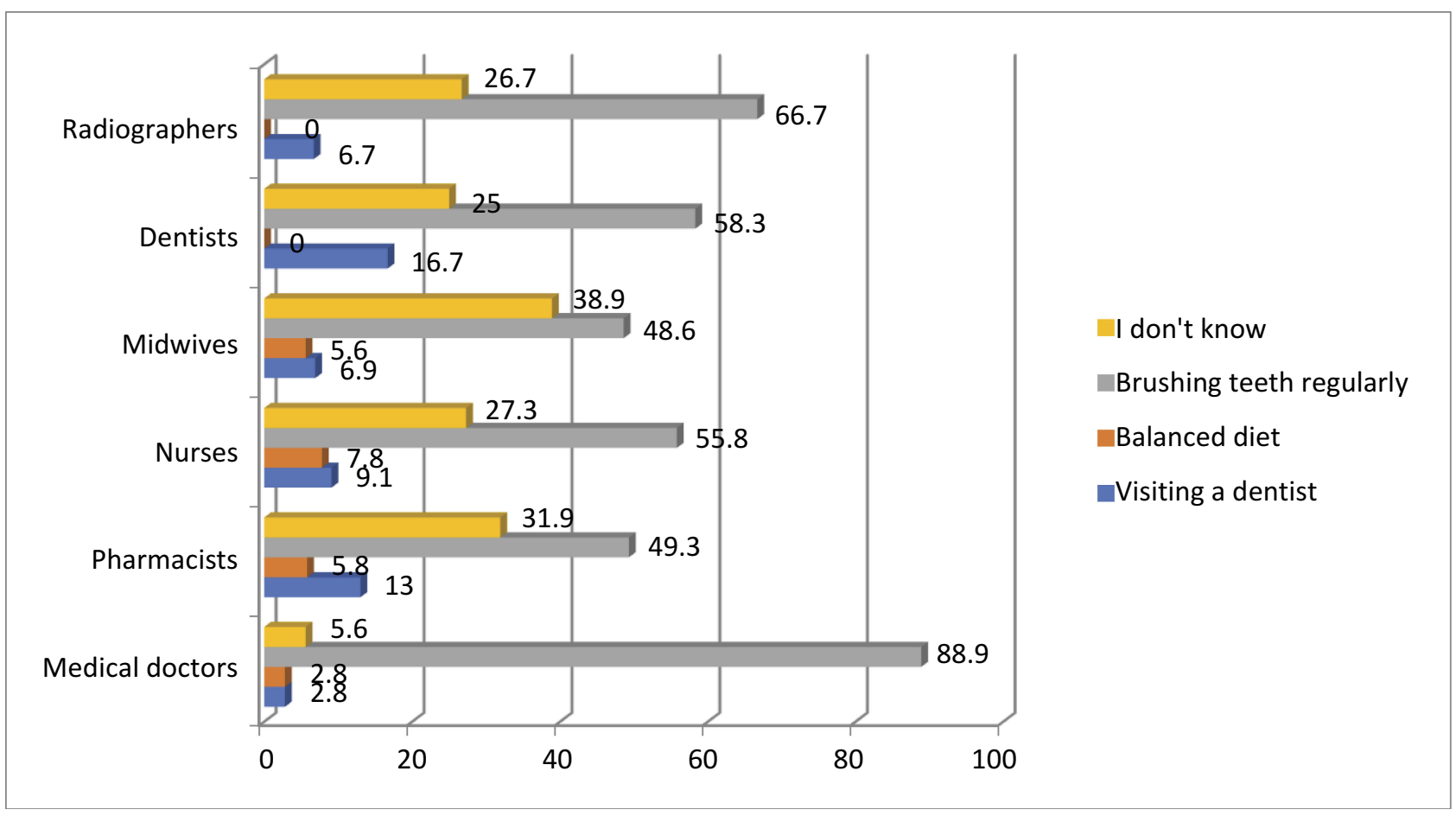

Figure I Health professional's responses to the question "Which dental problem needs a dental intervention; dental plaque or dental calculus?".

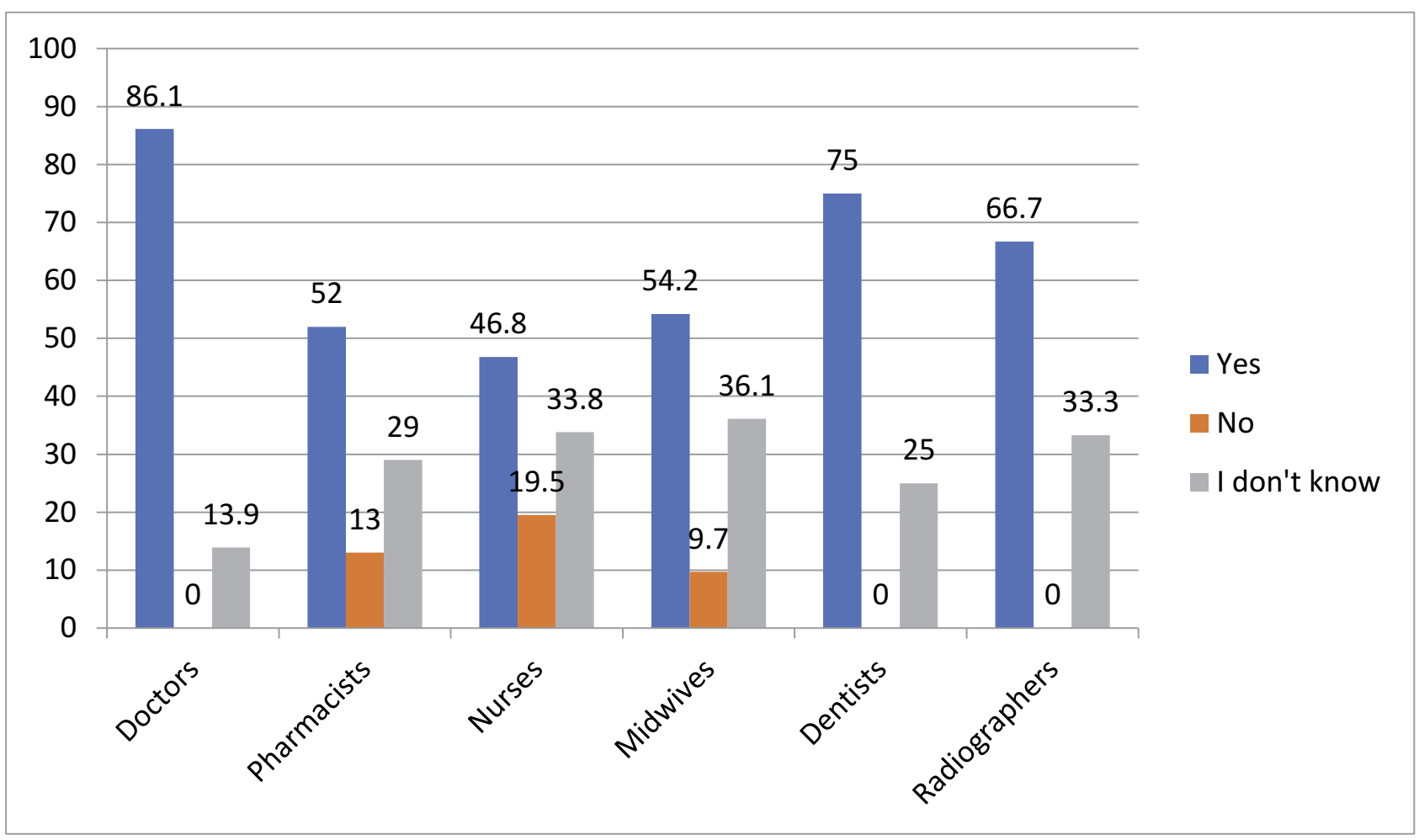

Figure 2 Health professional's responses to the question "Do you think fluoride toothpastes and mouthwash are important in maintaining dental hygiene?". 
There was a statistically significant difference $(\mathrm{P}=0.001)$ between the different health professionals.

\section{Oral Health Practice}

All of the doctors, pharmacists, nurses, dentists and radiographers and $(97.2 \%)$ of the midwives responded that they brush their teeth. However, statistically, significant differences were observed within the type of health professionals and having a training on oral health with regard to the "frequency of brushing teeth" $(\mathrm{P}=0.026)$ and $(\mathrm{P}=0.017)$ (Table 2). The majority of the respondent's; midwives (62.5\%), nurses (61\%), pharmacists (56.5\%), dentists $(50 \%)$ reported that they brush their teeth once per day compared with the majority of radiographers $(53.3 \%)$ and doctors $(50 \%)$ who had reported less frequently.

A statistically significant difference was observed on how much time they spent on brushing their teeth with regard to types of health professionals $(\mathrm{P}=0.014)$ and experience $(\mathrm{P}=0.03)$. The majority of the health professionals $(43.4 \%)$ reported that they spent significantly less than three minutes brushing their teeth. The majority of the study participants $(59.4 \%)$ reported that they use toothbrush and fluoride toothpaste for brushing their teeth. A comparison between different types of health professionals also showed statistically significant difference $(\mathrm{P}=0.012)$.

The majority of the health professionals (77.6\%) reported that they have at least once visited a dentist. There were differences among the different health professionals with regard to the main reason for their visit to a dentist. A greater number of doctors (47.2\%) and pharmacists $(37.7 \%)$ reported that it was for a routine checkup, while the majority of dentists $(50 \%)$, radiographers (46.7\%), midwives (43.1\%) and nurses (37.7\%) reported that it was due to a tooth pain. A statistically significant difference was also observed with respect to the main reason for the visit among those who took training on oral health when compared to those who $\operatorname{did} \operatorname{not}(\mathrm{P}=0.023)$.

The majority of the health professionals (56.6\%) reported that they sometimes counsel their patients to

Table 2 Comparison of Oral Health Practice Across Different Health Professionals, N=28I

\begin{tabular}{|c|c|c|c|c|}
\hline & & Gender & Profession & Training on Oral Health \\
\hline \multirow[t]{3}{*}{ Do you brush your teeth } & Chi-square & 3.00 & 5.49 & 0.50 \\
\hline & Df & I & 5 & I \\
\hline & Sig. & 0.223 & 0.359 & 1.000 \\
\hline \multirow[t]{3}{*}{ How often do you brush your teeth } & Chi-square & 1.65 & 20.41 & 8.12 \\
\hline & Df & 2 & 10 & 2 \\
\hline & Sig. & 0.438 & 0.026 & 0.017 \\
\hline \multirow[t]{3}{*}{ How much time do you spend brushing your teeth } & Chi-square & 3.094 & 22.265 & 2.010 \\
\hline & Df & 2 & 10 & 2 \\
\hline & Sig. & 0.213 & 0.014 & 0.366 \\
\hline \multirow[t]{3}{*}{ What material do you use for brushing } & Chi-square & 3.036 & 43.454 & 90.23 \\
\hline & Df & 5 & 25 & 5 \\
\hline & Sig. & 0.694 & 0.012 & 0.100 \\
\hline \multirow[t]{3}{*}{ Have you ever visited a dentist } & Chi-square & I.87I & 14.178 & 5.906 \\
\hline & Df & 3 & 15 & 3 \\
\hline & Sig. & 0.600 & 0.512 & 0.116 \\
\hline \multirow[t]{3}{*}{ Reason for the visit } & Chi-square & 4.953 & 24.346 & 11.299 \\
\hline & $\mathrm{Df}$ & 4 & 20 & 4 \\
\hline & Sig. & 0.292 & 0.228 & 0.023 \\
\hline
\end{tabular}


maintain their oral hygiene as part of general hygienic practice, with more number of doctors $(72.2 \%)$ taking the largest share as compared to the other health professionals. The different health professionals answered differently to the question "what beverage do you regularly drink the most in an average week?" with the majority of midwives $(44.4 \%)$, dentists $(41.7 \%)$, nurses $(41.6 \%)$ and pharmacists (36.2\%) reported coffee/tea/or milk while the majority of doctors $(36.1 \%)$ and radiographers $(53.3 \%)$ reported fruit juices and soft drinks/sports drink respectively.

\section{Barriers to Oral Health and Dental Care Services}

The majority of the health professionals reported limited finances and lack of adequate health/dental insurance as a barrier to oral health and dental care services $(80.1 \%)$ and $(70.8 \%)$ respectively (Table 3 ).

\section{Discussion}

Oral health knowledge was calculated by evaluating the answers of the respondents to various questions in the questionnaire and adding them to give a cumulative score. The responses were considered accurate if they answered according to the following: teeth should be cleaned twice daily, all vertical, horizontal and circular methods of brushing teeth are correct as needed, healthy gums look pink and firm, a dentist should be visited one to two times a year, dental calculus is the one that needs a dental intervention, oral health affects the rest of the body, the best method of preventing tooth decay is brushing regularly, sugary diets cause tooth decay and fluoride tooth paste and mouth wash are important in dental hygiene.

In the current study, it was observed that doctors followed by dentists had the highest mean knowledge score when compared with the other health professionals 4.67 and 4.5 respectively and the difference was also statistically significant among the different health professionals. This finding was in-line with similar studies conducted in King Fahad Medical City, Riyadh, and Ludhiana, India, where doctors had the highest mean score value compared with the other health professionals. ${ }^{17,18}$ This could be because doctors have much higher personal involvement with dental patients compared with other health professionals and took dental department attachments during their education programs. Dentists have especially their profession entirely focusing on dental health and as such, they would have more knowledge score than others. The reason for doctors having more knowledge score than dentists could be ascribed to the sample size of the study participants; as the sample size of doctors is three times that of the dentists, the figures may change if equal sizes had been take. Individual factors (knowledge differences) could also be possible reasons for the observed outcome.

The majority of the health professionals in the current study reported teeth should be cleaned twice per day. Studies suggest that brushing tooth twice-daily is significantly more effective than brushing once a day. ${ }^{19}$ The American Dental Association, the American Academy of Pediatric Dentists and the American Academy of Pediatrics also recommend twice per day brushing of a teeth for achieving better oral health outcomes. ${ }^{20,21}$

In the present study, the majority of the study participants agreed that sugary diets like soft drinks and juices cause tooth decay. This finding was in line with similar studies conducted in Riyadh and India, where it was reported that frequent consumption of sugary foods was associated with dental health and cause tooth decay. ${ }^{17,23} \mathrm{It}$ was reported that the inherent acids and sugars found in soft drinks were found to have both potential acidogenic and cariogenic effects resulting in dental caries and potential enamel erosion. ${ }^{24}$

There are many tooth brushing techniques being on practice and the most common ones are; Roll or Modified Stillman, Stillman's, Charters, Bass, Modified Bass, Fones, Leonard, and Scrub. ${ }^{25}$ However, there is no such a unanimous technique recommended for adults and children, as studies show that there are discrepancies in techniques recommended by dental professionals, dental associations and toothpaste and toothbrush companies. ${ }^{26}$ The Bass and Modified Bass methods were most frequently advocated for adults which showed better plaque control and reduction in gingival inflammation. ${ }^{26,27}$ On the other hand, the Scrub and Fones techniques were more frequently recommended for children. ${ }^{26}$ In the present study, the majority of the health professionals answered that the correct method of brushing teeth is horizontal. Some studies show that, based on improved plaque control and reduced gingival inflammation, the Horizontal Scrub technique was second only to the Modified Bass technique for being the most effective brushing technique; while the least effective was Fones's method. ${ }^{28}$

In the current study, a greater number of doctors followed by radiographers answered that the best method to prevent tooth decay is brushing teeth regularly. Brushing a tooth 
Table 3 Barriers To Oral Health And Dental Care Services, N=28I

\begin{tabular}{|c|c|c|c|c|c|c|c|c|c|c|}
\hline \multicolumn{3}{|l|}{ Barriers } & \multicolumn{6}{|c|}{ Profession } & \multirow{6}{*}{$\begin{array}{l}\begin{array}{l}\text { Chi- } \\
\text { square } \\
\text { value }\end{array} \\
2.959\end{array}$} & \multirow{3}{*}{$\begin{array}{l}\text { p- } \\
\text { value } \\
0.706\end{array}$} \\
\hline & & & \multirow{3}{*}{\begin{tabular}{|l|} 
Doctors \\
32 \\
88.9 \\
\end{tabular}} & \multirow{2}{*}{$\begin{array}{l}\text { Pharmacists } \\
56\end{array}$} & \multirow{2}{*}{$\begin{array}{l}\text { Nurses } \\
61\end{array}$} & \multirow{2}{*}{$\begin{array}{l}\text { Midwives } \\
55\end{array}$} & \multirow{2}{*}{$\begin{array}{l}\text { Dentists } \\
10\end{array}$} & \multirow{2}{*}{$\begin{array}{l}\text { Radiographers } \\
\text { II }\end{array}$} & & \\
\hline Limited finances & Yes & Freq. & & & & & & & & \\
\hline & & $\%$ & & 81.2 & 79.2 & 76.4 & 83.3 & 73.3 & & \\
\hline & No & Freq. & 4 & 13 & 16 & 17 & 2 & 4 & & \\
\hline & & $\%$ & 11.1 & 18.8 & 20.8 & 23.6 & 16.7 & 26.7 & & \\
\hline \multirow{4}{*}{$\begin{array}{l}\text { Lack of adequate } \\
\text { health/dental } \\
\text { insurance }\end{array}$} & \multirow[t]{2}{*}{ Yes } & Freq. & 26 & 54 & 54 & 48 & 8 & 9 & \multirow[t]{4}{*}{3.452} & \multirow[t]{4}{*}{0.631} \\
\hline & & $\%$ & 72.2 & 78.3 & 70.1 & 66.7 & 66.7 & 60.0 & & \\
\hline & \multirow[t]{2}{*}{ No } & Freq. & 10 & 15 & 23 & 24 & 4 & 6 & & \\
\hline & & $\%$ & 27.8 & 21.7 & 29.9 & 33.3 & 33.3 & 40.0 & & \\
\hline \multirow{4}{*}{$\begin{array}{l}\text { Limited awareness of } \\
\text { available dental care }\end{array}$} & \multirow[t]{2}{*}{ Yes } & Freq. & 28 & 57 & 65 & 55 & 9 & 13 & \multirow[t]{4}{*}{2.501} & \multirow[t]{4}{*}{0.776} \\
\hline & & $\%$ & 77.8 & 82.6 & 84.4 & 76.4 & 75.0 & 86.7 & & \\
\hline & \multirow[t]{2}{*}{ No } & Freq. & 8 & 12 & 12 & 17 & 3 & 2 & & \\
\hline & & $\%$ & 22.2 & 17.4 & 15.6 & 23.6 & 25.0 & 13.3 & & \\
\hline \multirow[t]{4}{*}{ Fear of pain } & \multirow[t]{2}{*}{ Yes } & Freq. & 29 & 48 & 53 & 50 & 8 & 12 & \multirow[t]{4}{*}{2.631} & \multirow[t]{4}{*}{0.757} \\
\hline & & $\%$ & 80.6 & 69.6 & 68.8 & 69.4 & 66.7 & 80.0 & & \\
\hline & \multirow[t]{2}{*}{ No } & Freq. & 7 & 21 & 24 & 22 & 4 & 3 & & \\
\hline & & $\%$ & 19.4 & 30.4 & 31.2 & 30.6 & 33.3 & 20.0 & & \\
\hline \multirow[t]{4}{*}{ Work schedules } & \multirow[t]{2}{*}{ Yes } & Freq. & 30 & 48 & 49 & 46 & 8 & 11 & 5.422 & 0.367 \\
\hline & & $\%$ & 83.3 & 69.6 & 63.6 & 63.9 & 66.7 & 73.3 & & \\
\hline & No & Freq. & 6 & 21 & 28 & 26 & 4 & 4 & & \\
\hline & & $\%$ & 16.7 & 30.4 & 36.4 & 36.1 & 33.3 & 26.7 & & \\
\hline Limited dental & Yes & Freq. & 18 & 48 & 49 & 44 & 10 & 9 & 6.206 & 0.287 \\
\hline professionals & & $\%$ & 50.0 & 69.6 & 63.6 & 61.1 & 83.3 & 60.0 & & \\
\hline & No & Freq. & 18 & 21 & 28 & 28 & 2 & 6 & & \\
\hline & & $\%$ & 50.0 & 30.4 & 36.4 & 38.9 & 16.7 & 40.0 & & \\
\hline Mistrust of health care & Yes & Freq. & 21 & 51 & 47 & 47 & 8 & 10 & 3.674 & 0.597 \\
\hline protessionals & & $\%$ & 58.3 & 73.9 & 61.0 & 65.3 & 66.7 & 66.7 & & \\
\hline & No & Freq. & 15 & 18 & 30 & 25 & 4 & 5 & & \\
\hline & & $\%$ & 41.7 & 26.1 & 39.0 & 34.7 & 33.3 & 33.3 & & \\
\hline Inability to recognize & Yes & Freq. & 26 & 55 & 54 & 49 & 11 & 11 & 4.947 & 0.422 \\
\hline signs of dental dis & & $\%$ & 72.2 & 79.7 & 70.1 & 68.1 & 91.7 & 73.3 & & \\
\hline & No & Freq. & 10 & 14 & 23 & 23 & 1 & 4 & & \\
\hline & & $\%$ & 27.8 & 20.3 & 29.9 & 31.9 & 8.3 & 26.7 & & \\
\hline
\end{tabular}


Table 3 (Continued).

\begin{tabular}{|c|c|c|c|c|c|c|c|c|c|c|}
\hline \multicolumn{3}{|l|}{ Barriers } & \multicolumn{6}{|c|}{ Profession } & \multirow{3}{*}{$\begin{array}{l}\begin{array}{l}\text { Chi- } \\
\text { square } \\
\text { value }\end{array} \\
3.525\end{array}$} & \multirow{3}{*}{$\begin{array}{l}\begin{array}{l}p- \\
\text { value }\end{array} \\
0.620\end{array}$} \\
\hline & & & Doctors & Pharmacists & Nurses & Midwives & Dentists & Radiographers & & \\
\hline \multirow[t]{4}{*}{ Lack of transportation } & \multirow[t]{2}{*}{ Yes } & Freq. & 23 & 49 & 52 & 44 & 10 & 11 & & \\
\hline & & $\%$ & 63.9 & 71.0 & 67.5 & 61.1 & 83.3 & 73.3 & & \\
\hline & \multirow[t]{2}{*}{ No } & Freq. & 13 & 20 & 25 & 28 & 2 & 4 & & \\
\hline & & $\%$ & 36.1 & 29.0 & 32.5 & 38.9 & 6.7 & 26.7 & & \\
\hline
\end{tabular}

twice a day for two minutes using fluoride toothpaste is recommended by the American Dental Association and this has achieved a clinically significant effect in plaque removal and thereby prevent progressive tooth decay. ${ }^{29}$

In the present study, the majority of the health professionals answered that oral health affects the rest of the body. Similar findings were reported by a study conducted in Riyadh. ${ }^{17}$ Studies show that, a decrease in overall quality of life, including chronic pain and suffering may result from dental caries throughout time. ${ }^{30}$ Furthermore, chronic medical conditions, including diabetes mellitus and cardiovascular disease were associated with poor dental health in adulthood. ${ }^{30}$ The majority of the respondents in the current study have also responded positively when asked about whether products like fluoride toothpaste and mouth wash were important in dental hygiene. It is reported that the use of a fluoride containing toothpaste enhances biofilm fluid and saliva fluoride concentration levels, and is associated with lower risk of caries and remineralization of teeth. ${ }^{31}$

Regarding oral health-related practices of the study participants, almost all of the health professionals reported that they brush their teeth. However, statistically, significant differences were observed about the frequency of brushing their teeth, with the majority of them reporting once per day while the others reported less frequently. This finding was similar to a study conducted in Ludhiana, India, in which once a day brushing of teeth was reported in approximately $50 \%$ of the health professionals. ${ }^{18}$ A similar study conducted in Riyadh also reported that $77.9 \%$ of the health professionals brushed their teeth only once in the morning. ${ }^{17}$ This finding was not inline with the recommendation by the American Dental Association which suggests brushing teeth twice a day as an effective method of maintaining oral health and preventing tooth decay. ${ }^{20}$

In the current study, the majority of the health professionals reported limited finances and lack of adequate health/ dental insurance as a barrier to oral health and dental care services. This could be attributed to the fact that in developing countries like Ethiopia, the monthly salary of the majority of public servants including health professionals (especially those working in public health facilities) is lower and thus hinders them from utilizing modern medical care including oral health and dental services. In Ethiopia, health professionals monthly salary is almost similar with the other nonhealth professionals and they on average earn around 12,500 ETB (Ethiopian Birr) (3860-39,700ETB) which is around $416 \$(128.6 \$-1323 \$)$ depending on the type of health profession and the position he/she had. Medical doctors and dentists earn relatively higher monthly salary than the other health professionals and it is around 20,800ETB (693\$) for medical doctors and 20,700 (690\$) for dentist and this is the average monthly salary as it may be higher or lower depending on their position and type of facility they are working in. Health insurance was also another important factor affecting the utilization of oral health and dental care services and this is true because in Ethiopia only few private sectors provide the service and it was only been given due consideration recently by the government as part of its health sector financing reform (HSFR) initiatives in 2011 by introducing the social health insurance (SHI) and Community Based Health Insurance (CBHI) programs and establishing the Ethiopian Health Insurance Agency (EHIA). Although there are improvements in health care utilization and access since the introduction of the system, there are still many challenges facing its implementation. ${ }^{32-34}$

\section{Limitation of the Study}

Lack of standardized questionnaire to assess oral health knowledge and practices and unavailability of comparable study instruments. The second limitation was concerning the genuineness of the reported practices, as the results of the present study relied on self-reported responses by the 
study participants which may be biased to commonly agreed standard practices.

\section{Conclusion}

Oral health-related knowledge of health professionals in Bahir Dar city is low. This could be regarded as a problem because health professionals are the ones who are regarded as sources of health information to the other population as they have better access to any kind of medical information more than others.

\section{Recommendations}

Oral health awareness of health professionals should be improved. Oral health topics must be incorporated into the health care professionals training programs and continuing medical education. Health professionals should master basic oral health-related knowledge and they should practice basic oral health care practices to become role models for their patients.

\section{Acknowledgment}

The authors would like to express their gratitude to all study participants for their cooperation and participation in the study.

\section{Author Contributions}

All authors contributed to data analysis, drafting or revising the article, gave final approval of the version to be published, and agree to be accountable for all aspects of the work.

\section{Funding}

The authors received no financial support for the research, authorship, or publication of this article.

\section{Disclosure}

The authors declared no potential conflicts of interest with respect to the research, authorship, or publication of this article.

\section{References}

1. Jackson SL, Vann WF Jr, Kotch JB, Pahel BT, Lee JY. Impact of poor oral health on children's school attendance and performance. $\mathrm{Am}$ J Public Health. 2011;101(10):1900-1906. doi:10.2105/AJPH.2010. 200915

2. Håkansson S, Sturesson A, Andersson P, Mårtensson C. Oral hygiene experience, knowledge of oral health and oral diseases and attitudes about oral health care-A questionnaire study among students of nursing in Zambia school of health and society dental hygienist programme. Essay in Oral Health. 2010.
3. Rabiei S, Mohebbi SZ, Patja K, Virtanen JI. Physicians' knowledge of and adherence to improving oral health. BMC Public Health. 2012;12(1):855. doi:10.1186/1471-2458-12-855

4. Riley III JL, Gilbert GH, Heft MW. Dental attitudes: proximal basis for oral health disparities in adults. Community Dent Oral Epidemiol. 2006;34(4):289-298. doi:10.1111/j.1600-0528.2006.00280.x

5. American Academy of Pediatric Dentistry. Clinical Guidelines: Adolescent Oral Health Care. Chicago, IL: American Academy of Pediatric Dentistry; 2012.

6. Weyant RJ, Manz M, Corby P, Rustveld L, Close J. Factors associated with parents' and adolescents' perceptions of oral health and need for dental treatment. Community Dent Oral Epidemiol. 2007;35 (5):321-330. doi:10.1111/j.1600-0528.2006.00336.x

7. Bakdash B. Current patterns of oral hygiene product use and practices. Periodontol 2000. 1995;8(1):11-14. doi:10.1111/j.16000757.1995.tb00041.x

8. Davies GM, Duxbury JT, Boothman NJ, Davies RM, Blinkhorn AS. A staged intervention dental health promotion programme to reduce early childhood caries. Community Dent Health. 2005;22(2):118-122.

9. Lin S, Mauk A. Addressing dental diseases in rural India. Implementing public health interventions in developing countries. Int J Oral Health Sci. 2014;105-129.

10. Kaimenyi JT, Ndungu FL, Maina SW, Chindia M. Oral hygiene habits and dental health awareness of Kenyan children aged 9-15 years in a peri-urban and urban school. East Afr Med J. 1993;70(2):67-70.

11. Paik DL, Moon HS, Horowitz AM, Gift HC, Jeong KL, Suh SS. Knowledge of and practices related to caries prevention among Koreans. J Public Health Dent. 1994;54(4):205-210. doi:10.1111/ j.1752-7325.1994.tb01216.x

12. Tewari A, Gauba K, Goyal A. Evaluation of existing status of knowledge, practice and attitude towards oral health of rural communities of Haryana-India. J Indian Soc Pedod Prev Dent. 1991;9(1):21-30.

13. Asadi SG, Asadi ZG. Chewing sticks and the oral hygiene habits of the adult Pakistani population. Int Dent J. 1997;47(5):275-278. doi:10.1002/j.1875-595X.1997.tb00789.x

14. Al-Tamimi S, Petersen PE. Oral health situation of schoolchildren, mothers and schoolteachers in Saudi Arabia. Int Dent J. 1998;48 (3):180-186. doi:10.1111/j.1875-595X.1998.tb00475.x

15. Normark S, Mosha HJ. Knowledge, practices and dental health among rural Tanzania children. Afr Dent j. 1989;3(2):24-33.

16. Ethiopia CC. Summary and Statistical Report of the 2007 Population and Housing Census. Addis Ababa, Ethiopia: Federal democratic republic of Ethiopia population census commission; 2008:1.

17. Baseer MA, Alenazy MS, AlAsqah M, AlGabbani M, Mehkari A. Oral health knowledge, attitude and practices among health professionals in King Fahad medical city, Riyadh. Dent Res J. 2012;9 (4):386.

18. Kaur S, Kaur B, Ahluwalia SS. Oral health knowledge, attitude and practices amongst health professionals in Ludhiana, India. Dentistry. 2015;5(7):1.

19. Nguyen L, Häkkinen U, Knuuttila M, Järvelin MR. Should we brush twice a day? Determinants of dental health among young adults in Finland. Health Econ. 2008;17(2):267-286. doi:10.1002/hec.1258

20. American dental association toothbrushes; 2012. Available from: http://www.ada.org/1321.aspx.

21. American academy of pediatric dentistry fast facts: preventive step 1 —good home care; 2012. Available from: http://www.aapd.org/ assets/1/7/FastFacts.pdf.

22. American academy of pediatrics A pediatric guide to children's oral health; 2010. Available from: http://www2.aap.org/oralhealth/docs/ OralHealthFCpagesF2_2_1.pdf.

23. Bhoopathi PH, Reddy PR, Kotha A, Mancherla M, Boinapalli P, Samba A. Oral health related knowledge, attitude and practices among the primary health care workers of a district in India. J Int Soc Preventive Community Dent. 2014;4(Suppl 1):S11. doi:10. 4103/2231-0762.144563 
24. Cheng R, Yang H, Shao MY, Hu T, Zhou XD. Dental erosion and severe tooth decay related to soft drinks: a case report and literature review. J Zhejiang Univ Sci B. 2009;10(5):395-399. doi:10.1631/ jzus.B0820245

25. Janakiram C, Varghese N, Ramanarayanan Venkitachalam JJ, Vineetha K. Comparison of modified Bass, Fones and normal tooth brushing technique for the efficacy of plaque control in young adults-A randomized clinical trial. J Clin Exp Dentistry. 2020;12(2): e123. doi: $10.4317 /$ jced.55747

26. Wainwright J, Sheiham A. An analysis of methods of toothbrushing recommended by dental associations, toothpaste and toothbrush companies and in dental texts. Br Dent J. 2014;217(3):E5. doi:10.1038/sj. bdj.2014.651

27. Poyato-Ferrera M, Segura-Egea JJ, BullónFernández $P$ Comparison of modified Bass technique with normal toothbrushing practices for efficacy in supragingival plaque removal. Int Int $J$ Dent Hyg. 2003;1:110-114. doi:10.1034/j.1601-5037.2003.00 018.x

28. Patil SP, Patil PB, Kashetty MV. Effectiveness of different tooth brushing techniques on the removal of dental plaque in 6-8 year old children of Gulbarga. J Int Soc Prev Community Dent. 2014;4:113-116. doi:10.4103/2231-0762.138305
29. Gallagher A, Sowinski J, Bowman J, et al. The effect of brushing time and dentifrice on dental plaque removal in vivo. Ame Dent Hygienists Assoc. 2009;83(3):111-116.

30. Hollister MC, Weintraub JA. The association of oral status with systemic health, quality of life, and economic productivity. J Dent Educ. 1993;57(12):901-912.

31. Newby EE, Martinez-Mier EA, Zero DT, et al. A randomised clinical study to evaluate the effect of brushing duration on fluoride levels in dental biofilm fluid and saliva in children aged $4-5$ years. Int Dent J. 2013;63:39-47. doi:10.1111/idj.12072

32. Ethiopian health insurance agency. evaluation of community-based health insurance pilot schemes in ethiopia. Final Report. Ethiopia: Addis Ababa; May 2015.

33. Yilma Z, Mebratie A, Sparrow R, Dekker M, Alemu G, Bedi AS. Impact of Ethiopia's community based health insurance on household economic welfare. World Bank Econ Rev. 2015;29(suppl_1):S16473. doi:10.1093/wber/lhv009

34. Jembere MY. Community based health insurance scheme as a new healthcare financing approach in rural ethiopia: role on access, use and quality of healthcare services, the case of tehuledere district, south wollo zone, Northeast Ethiopia. Family Med Med Sci Res. 2018;7:02. doi:10.4172/2327-4972.1000227
Journal of Multidisciplinary Healthcare

\section{Publish your work in this journal}

The Journal of Multidisciplinary Healthcare is an international, peerreviewed open-access journal that aims to represent and publish research in healthcare areas delivered by practitioners of different disciplines. This includes studies and reviews conducted by multidisciplinary teams as well as research which evaluates the results or conduct of such teams or healthcare processes in general. The journal covers a very wide range of areas and welcomes submissions from practitioners at all levels, from all over the world. The manuscript management system is completely online and includes a very quick and fair peer-review system. Visit http://www.dovepress.com/testimonials. php to read real quotes from published authors. 